\title{
EL APRENDIZAJE DE LA FELICIDAD
}

\author{
$M^{a}$ Dolores Avia \\ Universidad Complutense, \\ Departamento de Psicología Clínica \\ Facultad de Psicología - Campus de Somosaguas (Madrid)
}

Partes de este documento fueron presentados, con variaciones, a los cursos de verano de la UCM en el Escorial (2007) y en las Universidades de Málaga (2007) y Pamplona.(2008)

\section{RESUMEN}

En este trabajo se examinan algunos procedimientos $y$ estrategias para la mejora de la satisfacción con la propia vida. Las consideraciones hedonistas y eudaimónicas, las implicaciones del constructo de autocompasión y la propuesta acerca de las fortalezas y virtudes humanas se describen con el objetivo de ir aproximándonos a la meta de ayudar a las personas a sentirse más satisfechas con su vida. Frente a las posturas de muchos intelectuales y corrientes de pensamiento, se afirma la utilidad de estas sugerencias, a la vez que se reconocen sus limitaciones.

Palabras clave: Psicología positiva, fortalezas, autocompasión, bienestar subjetivo 


\section{ABSTRACT}

Strategies and procedures to enhance subjetive wellbeing are examined. We describe briefly the utility of hedonistic and eudaimonic considerations of well-being, as well as the implications of the self-compassion construct and the character strengths and virtues approach. While many cultural movements and recognized thinkers held sceptical or negative views about those proposals, we held an optimistic and supportive view about them, despite their limitations.

\section{Key Words: Positive psychology, human strengths, self- compassion, subjective well-being}

\section{A modo de introducción}

Nuestro maestro -lo fue de muchos- J.L. Pinillos solía contar que el ciclo evolutivo de un profesor se puede resumir en la idea de los tres Sanchos: al principio, Sancho el Bravo; a la mitad, Sancho el Fuerte y al final, Sancho Panza. Mi experiencia -no estoy nada segura de que coincida con la opinión de mis alumnos- refleja muy bien ese ciclo: empecé a las bravas- qué remedio cuando es uno joven y se siente frágil- la experiencia me fortaleció, y para mí que estoy muy próxima a la etapa de Panza. Esto no es más que una forma de justificar que mi colaboración a este número de la revista Análisis y Modificación de Conducta, que inicia una nueva y seguro que fructífera etapa, en la que me siento muy honrada en participar, no sea propiamente un artículo de investigación ni de elaboración teórica, lo que habría hecho hace unos años, sino más bien una reflexión, sentida y pensada, sobre una de las áreas en las que recientemente se ha embarcado la psicología, con acierto para muchos y errores, desaciertos y omisiones para otros: el análisis de las cualidades mejores y más positivas de los humanos, el estudio de la felicidad. Seguro que otros colaboradores ofrecerán trabajos más canónicos; por mi parte, más allá de investigaciones concretas, es esto lo que me ocupa y lo que he querido compartir. 


\section{2. ¿Se puede buscar la felicidad?}

Según una antigua tradición, cuando los dioses crearon al hombre, asustados por la perfección de su obra, se reunieron para buscar algún modo de que el ser recién creado no fuese tan perfecto que se convirtiera asimismo en un dios. Todos convinieron en que debían privarle de alguna cualidad fundamental que lo distinguiese definitivamente de los dioses y, tras algunas discusiones, decidieron retirar de entre sus cualidades la capacidad de ser feliz. Enseguida surgió el problema de dónde esconderían esa virtud, la felicidad, de forma que él no la encontrara. Algunos sugerían ponerla en lo más alto de las montañas, pero otros pensaron que los hombres, listos como los habían hecho, se las ingeniarían para alcanzarla, como si ya hubiesen visto que muchos iban a perder la vida tratando de escalar el K2; otros consideraron más adecuado sumergir la felicidad en el fondo de los océanos, pero la mayoría sabía que ahí también corría peligro (al cabo de muchos siglos, todavía estamos encontrando en el fondo del mar bustos desconocidos de Adriano, y los ingenieros aeronáuticos están ya poniendo torretas en el fondo del mar para aprovechar la energía de las corrientes marinas)

Al fin alguien tuvo una buena idea: pongamos la felicidad en el interior de cada hombre: ahí seguro que no la encontrarán. La sugerencia fue aceptada por todos, y desde entonces, la historia humana ha sido una búsqueda constante y frustrada en pos de la felicidad externa. La hemos buscado en la lotería, en los viajes, en los premios, en las bodas, en los hijos, en los padres... en todo, menos donde estaba: dentro de nosotros. Es verdad que algunos de esos intentos han producido pedacitos, muchas veces efímeros, de felicidad -la lotería de los que menos- y todos ellos, sumados, han dado algún fruto. Sin embargo, como dice la leyenda, hay que buscar el tesoro en otro sitio, precisamente en uno en el que muchos ni siquiera han pensado.

La búsqueda de la felicidad, a pesar de ser el objetivo más importante de la vida, no ha tenido muy buena prensa. Con la cantidad de asuntos importantes que quedan por estudiar, dedicarnos a lo que nos puede hacer felices parece casi una frivolidad. Pero además, para muchos, es una utopía. 
Si seguimos a uno de los últimos sabios europeos, el filósofo y crítico George Steiner, existen múltiples razones para la tristeza del pensamiento. Resumiendo los argumentos de uno de sus muchos y elegantes libros, los humanos tendemos intelectualmente a la tristeza, al menos por diez razones (Steiner, 2007)

El pensamiento humano no sabe de certezas

El pensamiento humano es incontrolable

El pensamiento humano es muy improbablemente original

Dada su dependencia del lenguaje, ambiguo y ficticio, la verdad en el pensamiento es rara e infrecuente

El pensamiento humano es derrochador, despilfarrador, desordenado, inmanejable

Grandes sombras se interponen entre el pensar y el hacer

La realidad es inaccesible. El pensamiento puede ser ficción

El idiolecto del pensamiento persigue un imposible: hasta en el amor más intenso puede haber una profunda desatención hacia la persona amada que ésta muy probablemente nunca conocerá

Pensamos todos incesantemente, pero no se puede enseñar a nadie a tener pensamientos que merezcan la pena

La perenne y urgente interrogación sobre la existencia, la mortalidad y lo sagrado no llega a ninguna parte.

¿Existe, entonces una tendencia natural a la tristeza? ¿Es más natural sentirse triste que alegre? ¿Tenemos que aprender a ser alegres y luchar contra la melancolía a la que de manera natural parecemos estar condenados? La infelicidad, según se desprende de lo enumerado por Steiner, es inherente a nuestra esencia: la felicidad, 
ya que depende de unos pensamientos que la impiden. Mi compañero $C$. Vázquez me ha sugerido que, ya que me he centrado en las diez razones de Steiner, se las rebata una a una, pues según él, no son ciertas, son falaces. No sé si es que es más optimista que yo, o al contrario (éste podría ser un buen punto para el debate: ¿quien es más optimista, el que no cree en las razones que llevan a la tristeza, como él en este caso, o el que puede creer en su verdad, como me ocurre a mí, pero cuya verdad no me interesa porque no afecta, creo yo, a la mayoría de los procesos que nos ocurren? ¿Qué es mejor para el optimismo, ser ateo respecto a las razones de la tristeza, como Vázquez, o agnóstico, como yo?)

Yo, desde luego, creo que, por centrarme en una de las razones enumeradas, en medio de una supuesta, íntima comunión con alguien, ese alguien puede de pronto pensar en las batuecas o en algo negativo o crítico sobre nosotros, pero ¿merece esa realidad posible, para mí irrebatible, negar o limitar la realidad, mucho más fecunda, de ese encuentro? ¿Vamos a sufrir por lo imperfecto de nuestro pensamiento, o asombrarnos ante una admirable imperfección que nos lleva, entre otras cosas, a creernos importantes, únicos o necesarios, aunque evidentemente no lo somos, o a mantener esperanzas e ilusiones en situaciones en que, vistas las cosas desde fuera, parece estar todo perdido? No es mi intención entrar a discutir con los sabios, sino más bien acercarme a la humilde sabiduría de las personas felices.

Los humanos parecemos tendentes a olvidar todas esas, y muchas otras razones que podríamos aducir, que nos conducen a la melancolía y al desencanto para encontrarnos fácilmente implicados en ficciones que nos llevan a paraísos puede que artificiales, pero eficaces. ¿Lo hacemos de manera consciente, sobreponiendo el optimismo de la voluntad al pesimismo intrínseco de la inteligencia, como señalara Gramsci? ¿Tenemos que esforzarnos en ahuyentar, a base de voluntarismos, los fantasmas reales que amenazan constantemente nuestra efímera y minúscula existencia? Yo diría que no. He escrito "olvidar" esas y otras muchas razones que nos amenazan, y ese proceso de olvido es, también, un proceso mental inherente al pensamiento humano. Sé bien que los dos adjetivos anteriores, efímera y minúscula, aplicados a algo tan importante como la pro- 
pia vida, resultarán desagradables a la mayoría. Pero no sólo eso: nos parecen irreales. La ley de la realidad aparente que Frijda formuló para las emociones refleja muy adecuadamente este proceso: no nos mueven emocionalmente los sucesos reales, sino aquellos aprehendidos como reales. Por eso podemos sufrir lo indecible por lo que percibimos como deslealtad o traición, aunque no lo sean, y permanecer impasibles ante amenazas muy serias para la supervivencia, como las derivadas del deterioro a que sometemos a nuestro planeta o el peligro personal que supone, por ejemplo, seguir fumando (Frijda, 1988). Nuestra existencia, aunque lo sea, no nos parece efímera, y mucho menos minúscula. Matizando, pues, la apreciación de Gramsci, la tendencia al optimismo se produce, al parecer, de manera espontánea; salvo en ciertas, aunque importantes ocasiones, no requiere esfuerzo. El pensamiento puede ser triste; pero el optimismo marca nuestras vidas y lo hace vitalmente, no tras denodados esfuerzos, como reflejan la evolución filogenética y el ciclo vital de la mayoría de las personas, que muestra en sus primeras fases una efusiva y arbitraria tendencia a la "grandeur", a creer que podemos hacer muchas más tareas de las que realmente están a nuestro alcance, aunque esa tendencia no sea impermeable a la realidad: los sucesos de la vida la van atenuando, si bien en la mayoría de los casos parece que sólo ligeramente, o al menos nunca del todo. Incluso en personas nonagenarias se observan procesos de sesgo y deformación benigna de la realidad que facilitan y promueven estados de ánimo favorables. Parecería extraño, por tanto, que se nos pida que enseñemos a la gente a ser más feliz cuando parece que lo natural es serlo. No debería ser difícil mantenernos de la manera que, según muchos datos, parece prevista en nuestra evolución.

Ocurre, creo yo, que hace tiempo que la vida que vivimos no tiene mucho que ver con lo natural. No es natural volar si uno no es un pájaro, como no es natural operarse, ponerse pendientes o piercings, o depilarse con cera. Aunque mucha gente, parece que la mayoría, desdeña con éxito las razones mentales que pueden llevarnos a la tristeza, lo que también y eficazmente ayudan a realizar muchas terapias cognitivas, hay en nuestro medio sociocultural algunos aspectos que no ayudan precisamente a ello. Uno de los más graves es el tiempo, o más precisamente, la falta de tiempo. Algunos nos 
escandalizamos cuando oímos a alguien decir que no tiene tiempo para leer, pero casi todos estaríamos de acuerdo en que apenas tenemos tiempo para ver a las personas que más nos interesan. No tenemos tiempo para promover nuestro bienestar, a veces por motivos tan irrisorios como tener que ir a una terapia para estar mejor, o ir a una clase de yoga o un masaje que nos relajen. Por tanto, empiezo por señalar la primera condición para ser más feliz: comprometerse con esa meta, recordarnos y hacernos concientes de que vivir mejor y ser más felices nos importa, y nos importa más que tener renombre, ganar dinero o terminar un trabajo que a veces no nos reporta nada pero que nos hemos comprometido en terminar. En su libro "El arte de la felicidad" el Dalai Lama dice textualmente: "Creo que el propósito fundamental de nuestra vida es buscar la felicidad. Tanto si se tienen creencias religiosas o no, todos buscamos algo mejor en la vida. Así pues, el movimiento fundamental de nuestra vida nos encamina en pos de la felicidad".

Mencionaré algunos procedimientos para estar mejor y más implicados en esta interesante y muchas veces pospuesta tarea vital: intentar vivir la mejor de las vidas que tenemos a nuestro alcance, o si se prefiere, utilizando unos términos que hace tan solo unos años resultaban obsoletos y hoy han vuelto a tener vigencia científica, convertirnos en lo que podemos y queremos ser, crecer personalmente. No puedo dejar de recordar a Jose Luis Sampedro, quien en charlas sobre economía ha señalado repetidamente y con mucho humor que lograr sacar lo mejor de cada uno, aquello para lo que estamos más capacitados y que nos puede producir mucho bienestar es una tarea fácil, sólo que no interesa a nadie: interesa más el dinerito.

\section{La investigación sobre bienestar: algunas sugerencias}

Antes de entrar en detalles, quiero recordar que no todo el mundo está igualmente capacitado para la felicidad, y ello no parece debido al mero efecto de las circunstancias. La capacidad de disfrutar de la vida suele ser un valor estable, muy probablemente afectado por características biológicas, temperamentales o por rasgos semipermanentes muy consolidados desde las primeras etapas de la vida. Eso implica que los programas dedicados a incrementar el bienestar 
subjetivo de las personas tienen sus límites. El equipo que dirige Sonia Lyubomirski (Lyubomirski, Sheldon y Shkade, 2005) ha señalado que esos límites se encuentran en torno al $50 \%$, que correspondería al punto fijo, la línea base de satisfacción, por así decir, de cada uno, sobre el cual actuarían los programas de intervención, que pueden permitir incrementarlo hasta en un $40 \%$, que no está nada mal. Siempre según la misma autora, el $10 \%$ restante se debe al efecto incontrolable de las circunstancias. Fíjense cómo han cambiado nuestros paradigmas: recordando a Rostand, ¿qué se hicieron de las nieves de antaño, que fue de aquellos pronósticos, esos sí que optimistas, de los primeros conductistas, los que convertían en sabios, con los debidos entrenamientos, hasta a los más zoquetes? El modelo estándar de ciencia social, como han señalado algunos, hace tiempo que ha rechazado la idea de los humanos como infinitamente maleables. Sin embargo, no hay que equivocarse: naturalmente que las circunstancias afectan enormemente al nivel de felicidad que sentimos, sólo que las circunstancias objetivas no significan mucho; lo importante es cómo esas circunstancias son procesadas y vividas por las diferentes personas, y ahí es donde aparecen enormes diferencias en los procesos cognitivos y motivacionales que de manera directa determinan la felicidad. Por otro lado, hasta ese $40 \%$ de incremento antes citado se debe a factores que están bajo control directo de las propias personas, es decir, a un factor tan importante como la propia voluntad, paradójicamente excluído en los análisis de antaño.

Cuando hace ya bastantes años empecé en la UCM a impartir un curso de Doctorado sobre emociones positivas y optimismo, examiné con mis alumnos lo que fue uno de los programas pioneros para promover la felicidad. Fue el año 1994-95 y el curso se llamaba "Distorsiones positivas: implicaciones para la salud mental". Me refiero al programa de Michael Fordyce, (1983) que no tuvo nunca mucha repercusión, pero del cual quiero recordar algunos puntos que posteriormente han coincidido con otros programas más precisos. Entre otras indicaciones, Fordyce subrayaba la importancia de estar activo y ocupado, a ser posible en una tarea exigente desde el punto de vista físico -mens sana in corpore sano- y mejor si la tarea era compartida con otros y revestía sentido e importancia para quien la hacía. Otras dos recomendaciones que posteriormente han sido es- 
tudiadas eran mantenerse centrado en el momento presente - y no, como tantas veces, hacemos, dar vueltas al pasado o anticipar futuribles: lo más seguro que tenemos es el presente, que maltratamos a favor del ayer y del mañana. Pero, recordando a Quevedo, Ayer se fue, mañana no ha llegado; / hoy se está yendo sin parar un punto:/ soy un fue, y un será, y un es cansado.... No esperemos en vano a terminar la carrera, casarnos, tener el niño o jubilarnos: lo que queramos hacer, hagámoslo hoy- $\mathrm{y}$ "Desarrollar un estilo de personalidad saludable", a lo que me referiré posteriormente.

Hace algunos años, y sin mucha sistemática, C. Vázquez y yo señalamos algunas líneas a seguir en el aprendizaje del optimismo, algunas de las cuales quiero recordar brevemente (Avia y Vázquez, 1997). Mencionábamos, en primer lugar, la importancia de ponernos metas alcanzables que tuvieran sentido. Esto, sin duda fundamental, ha sido señalado por muchos modelos psicológicos y por diversas formas de terapia. No añadimos entonces unos breves y sencillos recordatorios con los que uno de mis maestros, el profesor Fred Kanfer, ya desaparecido, ayudaba a sus pacientes a establecer sus metas:

Think small - Piensa en pequeño

Think positive - Piensa en positivo

Think possible - Piensa en posible

Think behavior - Piensa en conducta

Think ahead - Piensa de antemano (Kanfer y Schefft, 1988)

\section{Un brevísimo ejemplo:}

Aplicar "Piensa en pequeño" supondría pasar de proponerse "escribir una novela" a "mañana voy a escribir tres páginas"; "Piensa en positivo" iría de "me gustaría no discutir tanto con mi pareja" a "voy a prestarle mucha atención cuando me habla", tarea, a veces ardua donde las haya; "Piensa en posible" sugeriría, mejor que "a ver 
si gano un premio con mi novela, "cuando la tenga, la presentaré a un concurso"; "Piensa en conducta" llevaría a traducir una meta tan loable como " quiero ser mejor persona" por "voy a ayudar a terminar las tareas de casa sin refunfuñar", ejercicio muy adecuado para algunos caballeros y la mayoría de los adolescentes, y "Piensa de antemano" sugeriría, por ejemplo proponerse "para mi novela voy a escribir tres páginas diarias de lunes a viernes (los fines de semana probablemente no podré).

También señalábamos en su momento lo importante que es mirar hacia fuera o tratar de volcarse al exterior (pensar mucho en uno mismo es una mala receta para la felicidad, aunque sea con el propósito de mejorar: mucho más útil es "el noble olvido de sí mismo", de que hablaba Bertrand Russell), aceptarse uno mismo como es, tratar de ser valiente para defender las propias necesidades y enfrentarse a muchas situaciones de la vida, educar la capacidad de goce y fomentar actividades lúdicas y practicar la cordialidad y las relaciones profundas e íntimas con los demás. La mayoría de esas sugerencias han recibido atención experimental y han mostrado unos efectos beneficiosos para la satisfacción de los que trataré enseguida.

\section{HEDONISMO}

Desde que la que se ha llamado "Psicología positiva" se empezó a poner de moda, han abundado las sugerencias basadas en la parte más sencilla y fácil de aplicar de estos programas, los procedimientos que incrementan directamente el placer y tratan de cultivarlo tanto en la parte más inmediata, el presente, como también en la reconsideración del pasado y la anticipación del futuro, lo cual ya implica procesos más complejos. Todos estos procedimientos hedonistas se fundamentan en la persecución de actividades placenteras y en la reducción de los estados negativos, y han promovido estrategias interesantes como el saboreo, (Bryant, 2007) aquello a lo que nosotros llamábamos cultivar la capacidad de goce, (no consumir directamente lo que nos produce placer, sino paladearlo despacio, no sólo en los aspectos más físicos, sino todas nuestras experiencias); también hacerse muy consciente y estar presente y atento ante todas ellas, lo que se ha llamado mindfulness, o atención plena, a la 
que aludiré más de una vez. Uno puede aprender a darse pequeños premios que habitualmente no se da, como algún regalo, tiempo libre, dejar para mañana lo que podría hacer hoy, algún capricho o simplemente darse permiso para hacer algo que se pueda permitir y que no suponga riesgo.

Muchas veces el impedimento a la felicidad es el pesar o insatisfacción respecto a algo que no tiene remedio, bien por la propia conducta o por los agravios producidos por otros en el pasado. Los procedimientos para instalar el perdón y reconciliarse con el propio pasado están empezando a ser aceptados por los psicólogos y a mostrar ciertos resultados. (Worthington, Sandage, y Berry, 2000), y también existen desde hace tiempo métodos para enseñar optimismo y esperanza a adultos y niños (v. por ej, Gillham y otros, 1995).

El acercamiento hedonista supone sin duda un cambio y una mejora importante para algunas personas, como aquellas que se guían preferentemente por el deber, no se tienen mucho en cuenta a sí mismas, quizá aquellas a las que se llamó en su momento personalidades tipo $\mathrm{C}$, o tienen dificultades para gratificarse, bien sea por razones educativas, ideológicas, religiosas o como decía antes, porque no tienen tiempo. Un planteamiento hedonista de la felicidad es, sin embargo, insuficiente y sus efectos han mostrado ser eficaces pero de corta duración.

\section{EUDAIMONIA}

Muchos autores han recordado que una vida satisfactoria no puede asociarse únicamente con el placer, sino más bien con el compromiso y con encontrar sentido en lo que uno hace. La realización de los deseos no siempre es beneficiosa para la felicidad, y las personas sienten una gratificación más profunda cuando hacen no exactamente lo que quieren, sino lo que sienten que tienen que hacer. Esta es la crítica que hacen a los hedonistas los defensores de un punto de vista eudaimonista de la felicidad, aunque sus planteamientos no son contrarios a ellos y muchos resultados empíricos son perfectamente complementarios. La auténtica felicidad, según esto, sólo puede conseguirse como resultado de un funcionamiento psicológico óptimo, sería la consecuencia de que las personas es- 
tén desarrollando al máximo su verdadera naturaleza. Filósofos y pensadores han coincidido en que no hay verdaderos placeres que no surjan de necesidades genuinas y Spinoza insistió en que la verdadera libertad personal consiste en seguir las propias leyes, no las dictadas por otros.

Los modelos psicológicos que han reflexionado sobre las cualidades fundamentales que parecen requerirse para que se dé la felicidad han hablado entre otras de las siguientes: Deci y Ryan (2000) en su bien conocida teoría de la autodeterminación, insisten en que no es posible un verdadero y profundo bienestar si uno no satisface las tres necesidades básicas de autonomía, competencia y afiliación o creación de vínculos afectivos. Además debe guiarse por metas consistentes con dichas necesidades así como con los propios intereses y valores, de forma que si no se reconocen o se reconocen pero no se satisfacen, es fácil que las personas se embarquen en necesidades sustitutorias y funcionen por motivaciones extrínsecas como el deseo de reconocimiento, poder, o la búsqueda de admiración que, aunque se consigan, no generan satisfacción duradera. En cambio, percibir progresos hacia las metas importantes, internamente establecidas, consistentes con las propias necesidades, no sólo incrementa el bienestar sino también las sensaciones de integridad, congruencia y vitalidad. Esta última, resultado de disponer de energía para uno mismo, es, según las investigaciones, un potente indicador de bienestar eudaimónico. También es importante tener en cuenta un resultado empírico de este grupo que señala que el mayor bienestar está asociado no al cultivo y desarrollo de una cualquiera de estas necesidades, por muy importante que sea, sino al equilibrio entre las tres.

Con el planteamiento eudaimónico de la felicidad sintonizan las visiones orientales, bastante de actualidad en nuestro medio, que asocian precisamente la plenitud y felicidad con la ausencia de deseos. También los actuales entrenamientos en mindfulness propugnan una actitud consciente, abierta, atenta y no implicada emocionalmente, ante la vida.

Algunos procedimientos que se han utilizado para incrementar el bienestar en pacientes clínicos han tenido como referencia un modelo del bienestar bastante semejante al de la autodeterminación. El 
grupo de Giovanni Fava en Italia, se ha basado en el modelo de C. Ryff (Ryff y Singer, 1996) por su utilidad en ayudar a evaluar el estado de los pacientes así como a identificar objetivos en la terapia que proponen, que llaman terapia de bienestar (Fava et al, 1998). Este grupo defiende la conveniencia de aplicar este tratamiento, cuya forma de proceder no dejan del todo clara, a pacientes clínicos que han recibido el alta médica pero que, sin embargo, a juicio de sus terapeutas, no saben cómo procurarse bienestar. Es decir, a menudo al terminar con éxito un tratamiento terapéutico suelen quedar síntomas residuales que, aunque parezcan menores, tienen una repercusión muy importante en la calidad de vida de los pacientes, y a ellos va dirigida esta terapia. El modelo de bienestar de Ryff, en la que se basa, señala varios parámetros fundamentales que juntos definen un funcionamiento óptimo, y estos son sensación de control y competencia en la vida, percepción de un desarrollo o crecimiento personal, existencia de objetivos vitales claros, sensaciones de autonomía y autoaceptación y buenas y profundas relaciones con los demás. Si se examinan esas cualidades como dimensiones bipolares a o largo de un continuo, cuyos extremos opuestos serían, respectivamente, las sensaciones de descontrol o indefensión en la propia vida, la percepción de estancamiento y falta de rumbo, la indecisión, el perfeccionismo y la falta de empatía con los demás, se puede evaluar la situación de cada paciente en cada una de esas dimensiones y, según su resultado, orientar la terapia hacia las áreas deficitarias. A pesar de las abundantes publicaciones de este grupo, la utilidad de su procedimiento dista mucho de ser concluyente (Fava et. al., 2005)

\section{AUTORRESPETO}

La idea que en su día Vázquez y yo señalábamos de aceptar la propia realidad y no ser demasiado autocríticos, exigentes o perfeccionistas, ha recibido recientemente una atención explícita en el trabajo de una autora cuya propuesta me parece más interesante que la tan manida autoestima de la que tanto y tan mal a veces se habla. $\mathrm{K}$. Neff ha estudiado recientemente la repercusión que tiene sobre el bienestar lo que ella llama el respeto por uno mismo, una especie de 
empatía interna o sentimiento cariñoso y compasivo autodirigido en el que uno se compromete a hacer todo lo que pueda por producirse a sí mismo bienestar y eliminar lo que ha aprendido que le es dañino (Neff, 2003). Esto, que parece en principio simple, no lo es: solemos esforzarnos mucho en hacer cosas que consideramos valiosas; no tanto en hacer lo que responde a nuestros intereses genuinos, si no coinciden con aquellas, y muchas veces nos metemos en proyectos 0 empresas para ponernos a prueba, no para desarrollar lo que nos es más importante y nos llevaría a lo más central de nosotros mismos. K. Neff denomina a este concepto autocompasión, y para ilustrar su punto de vista recuerda lo que es la compasión hacia otros: sensibilidad y apertura a su dolor, sin pasar de ello o evitarlo, de forma que sea posible que aparezca un deseo de aliviarlos y curarlos con amabilidad y atenciones. Cuando esto se aplica al yo, no se dan juicios negativos por los propios fallos, fracasos o debilidades, sino que se comprenden como si fueran de otro y el individuo se ve, en definitiva, mucho más humildemente, como parte del ser humano. Para hacer esto es necesario practicar una forma equilibrada de atención a las propias emociones, no sobreidentificada con las que no nos gustan, sino distanciada de ellas, de forma que se puedan reconocer sin sufrir o tener que evitarlas; de nuevo, mindflulness.

El sentimiento compasivo hacia uno parece ser un buen predictor de que las personas se comparen menos con los demás, experimenten menos hostilidad y tengan menos necesidad de defenderse, estén menos pendientes de su presentación pública, den menos vueltas a lo que no hacen bien y tengan sentimientos de valía menos contingentes y más estables (Neff, y otros, 2007). Se presume también que la autocompasión puede tener valor preventivo (si tratamos de sufrir menos, empezamos a quitar lo que nos daña, como el estrés causado por nuestra propia actuación), y conlleve un contacto con el yo más auténtico y autónomo, más respuesta a los intereses intrínsecos y no a las amenazas externas y más claridad emocional sobre los propios procesos. Naturalmente, la llamada autocompasión es un indicador asociado a menor depresión y ansiedad (Neff y otros, 2007) 


\section{Fortalezas, capacidades y virtudes}

En el camino al aprendizaje de la felicidad se ha producido un hito importante con la publicación en 2004 del libro de fortalezas de Peterson y Seligman, fortalezas a las que yo me he referido como "repertorios positivos de personalidad" que debemos identificar y fomentar. Crecer supone siempre entrar en contacto con las propias fortalezas y desarrollarlas. Por ejemplo, la actitud compasiva con uno mismo a la que Neff se refiere se puede considerar parte de la fortaleza de autorregulación emocional, una forma de inteligencia emocional que consigue transformar emociones dolorosas o negativas en aprecio por uno mismo y capacidad de autocuidado, lo que implica una capacidad relativa de generar sentimientos cálidos y de reafirmación hacia uno mismo cuando más los necesita; su opuesto se puede ver en el modo de reaccionar al fracaso de las personas autocríticas que no sólo exageran y a veces distorsionan la importancia de sus fallos, sino que parecen tener una disfunción en el sistema de autorregulación emocional que les impide redirigir la atención a los aspectos mejores, positivos, de su vida, con el fin de recuperar el equilibrio emocional que las dificultades y fracasos alteran.

Con diversos resultados se han ido explorando ya las distintas fortalezas del carácter propuestas en la clasificación de Peterson y Seligman. Personalmente me gustaría señalar la importancia de dos cualidades muy poco exploradas hasta ahora, la valentía, y la humildad. El valor, que goza de un gran aprecio como cualidad moral, es fundamental para enfrentarse adecuadamente a la vida y desde luego en la terapia para afrontar psicológicamente nuestros miedos, debilidades y sombras. Recuerdo la definición propuesta de ella: "Disposición a actuar de forma voluntaria y probablemente con miedo en circunstancias peligrosas, habiendo apreciado correctamente los riesgos que ello implica y admitiendo que puede no lograrse el objetivo, que es preservar algún bien para uno mismo o los demás" (Shelp, 1984). Respecto a la humildad, de repercusiones importantísimas para trastornos que tienen como protagonistas una inflada visión del propio ego, su estudio supone una paradoja en la visión occidental que propugna la autoestima y el orgullo como cualidades generadoras de emociones positivas y por tanto fundamentales para 
el repertorio positivo de las personas. Sin embargo, como ha sido acertadamente señalado (Kachorek y otros, 2004), la humildad es una fortaleza que protege de la tentación del exceso de arrogancia y como tal implica una seguridad interna y una aceptación realista de uno mismo y su papel en el medio que supone una mayor sofisticación cognitiva que la de la mera autoestima alta, y por supuesto la grandiosidad o fanfarronería. Sería de gran interés examinar empíricamente si las personas humildes distorsionan ligeramente en su favor la visión de sí mismas como hacen la mayoría de las personas, es decir, si cometen esos "pecadillos" que tan certeramente señaló, entre otros y muy especialmente S. Taylor (Taylor y Brown, 1988; Taylor, 1989), o si, por el contrario, tienen un autoconcepto más realista, y de ser así, qué repercusiones tiene en su bienestar. Creo que es el momento de que incluyamos alguno de estos temas en nuestras apretadas agendas de investigación.

Respecto a otras fortalezas, mi trabajo se ha centrado en dos de las Ilamadas fortalezas transcendentales, pues con Seligman considero que además de una vida comprometida entre otras cosas con desarrollarse al máximo uno mismo, nos importa a todos vivir una vida con sentido en la que nuestros actos vayan más allá de nosotros mismos en un sentido amplio (Seligman, 2004). Erik Erikson (1982) hablaba de la "capacidad generativa" como la cualidad más relevante en una etapa evolutiva madura en la que las personas se preocupan por dejar algo útil para las generaciones futuras o, por en contrario, se agotan en sí mismas. Especialmente, me he centrado en dos de aquellas fortalezas, el agradecimiento y la apreciación de la belleza. y excelencia. Sobre esta última no hay apenas investigaciones, y sólo hace unos meses estoy ocupada en ella. Me ha interesado un reciente trabajo de Freedberg y Gallese, de las Universidades de Columbia y Parma, que muestra que el sentimiento físico de verse transportado por una obra de arte o emocionarse profundamente con una obra excelsa, como cuando en un concierto uno tiene que levantarse del asiento y gritar "bravo" ante una ejecución musical magnífica, o se admira ante un escrito cercano a la perfección, tiene mucho que ver con la empatía, y está basado en un mecanismo universal con una base neural clara, como muestran las neuronas espejo (Freedberg y Gallese, 2008). Dicho en términos muy simples, la apreciación de la 
belleza embellece y el reconocimiento de lo excelente nos acerca un poco a ello, y el mecanismo de identificación que parece subyacer a ello se refleja neurológicamente. Otros estudios (Lutz y otros, 2008). también indican una regulación neurológica de la emoción mediante prácticas positivas. Pero, ¿se puede entrenar a apreciar y reconocer mejor esos estados excelsos? En caso afirmativo, ¿cuál es la eficacia de esos posibles entrenamientos sobre el bienestar subjetivo?

Previamente hemos trabajado sobre inducción de agradecimiento mediante un diseño experimental en tres condiciones en el que se trabajó durante dos semanas con una muestra de estudiantes universitarios siguiendo, con variaciones, el procedimiento de 2003 de Emmons y McCullough (Martínez Martí, Avia y Hernández Lloreda, en prensa). Participaron 96 sujetos con una media de edad de 21 años, a los que aplicamos medidas pre, post y seguimiento tanto de gratitud como de emociones positivas y negativas, relaciones significativas con los demás y variables fisiológicas. El grupo experimental de agradecimiento tenía que anotar diariamente antes de acostarse las variables estudiadas y al final del registro, describir cinco sucesos diarios que pudieran ser motivo de agradecimiento. Otro grupo experimental centrado en barreras o escollos hacía lo mismo, pero anotando cinco dificultades diarias (económicas, interpersonales, laborales, domésticas) que le hubieran interferido en el logro de sus objetivos. Un grupo control realizó los mismos registros escribiendo al final cinco aspectos positivos/ negativos que hubieran llamado su atención durante el día. Los resultados mostraron claramente que hacerse consciente de los aspectos positivos de la vida y sentirse agradecido por ellos aumenta el afecto positivo; hubo diferencias. claras entre el grupo de agradecimiento y el que se centraba en las dificultades, estando el grupo control en un nivel intermedio. Después de la intervención, los participantes del primer grupo se encontraban más interesados, vigorosos, resueltos, fuertes y atentos: parece que el tratamiento tuvo, sobre todo, un efecto dinamizador.

En este trabajo tuvimos también ocasión de comprobar un supuesto importante para la psicología positiva, y fue que el afecto negativo no se vio afectado por la intervención, aunque las medias iban en la dirección esperable (menos afecto negativo en agradecimiento, seguido de control y de dificultades), lo cual pone de manifiesto que 
las emociones positivas y las negativas no son simplemente, como dice el sentido común, polos opuestos de una misma dimensión, y que, por tanto, podemos, si somos buenos terapeutas, ayudar a alguien a ser menos desgraciado sin que por eso le vayamos a hacer necesariamente más feliz; y a la inversa, en este tipo de intervenciones podemos, con suerte y buen trabajo, mejorar las emociones positivas, pero eso afecta poco o nada las a las "pasiones tristes", que diría Spinoza., que habrá que tratarlas aparte.

Los efectos de esta intervención se constataron también cuando era otra persona importante para el sujeto, ciega a la manipulación experimental, la que evaluaba el estado de ánimo de aquél, es decir, no estaban limitados al autoinforme, eran perceptibles para un observador externo. Sin embargo, y éste es un problema general en estos estudios, nuestra breve manipulación, aunque eficaz, fue efímera: la línea base de agradecimiento mostró una tendencia a volver a los niveles previos pasados 15 días, lo que indica que para modificar aspectos muy básicos de las personas, como la gratitud, la esperanza o el perdón, son necesarias intervenciones más duraderas y/o potentes, (los niveles basales de agradecimiento del grupo español en conjunto, en comparación con las muestras americanas, fueron bastante bajos.)

Este procedimiento ha mostrado en otros trabajos ser eficaz también a más largo plazo. El grupo de Seligman (Seligman, Oteen, Park y Peterson, 2005) comparó cinco estrategias para incrementar la felicidad en un grupo de sujetos reclutados por Internet. Encontraron efectos duraderos a los seis meses de terminada la práctica en dos de esas intervenciones: llevar un diario anotando sucesos positivos que ocurren cada día y dar gracias por ellos, y también utilizar las cinco principales fortalezas del carácter, identificadas en el cuestionario de los autores que aparece en su página web, en la vida diaria de manera nueva y creativa. Alguna sugerencia al respecto, para el cultivo de la apreciación de la belleza y excelencia, sería ir a un museo de nuestra ciudad al que no hayamos ido nunca, llevar un diario de estas cualidades observándolas en la vida cotidiana, sacar un rato para ver una puesta de sol, etc. 


\section{Algunas conclusiones}

A pesar de algunas acertadas críticas recientes (ver Lazarus, 2003; Prieto-Ursúa,, o Avia, 2006), la llamada "psicología positiva" está haciendo un gran esfuerzo por identificar, evaluar y fomentar. las propias fortalezas y desarrollarlas. Posiblemente en los próximos años asistamos a un desarrollo de las corrientes que, lejos de los movimientos nihilistas que tanto determinaron los inicios del siglo $X X$, parten de la base de que los seres humanos tenemos una tendencia biológica a mejorar, desarrollarnos y sacar el máximo partido de la vida, incluso en situaciones de sufrimiento y desgracia.

Respecto a lo enumerado hasta aquí, resumiré que para aprender a ser más felices lo primero que es necesario es cultivar actitudes saludables hacia uno mismo, lo que Fordyce llamaba un estilo de personalidad saludable. En una lectura ocasional y anecdótica, he encontrado hace poco esta perla: "Vigila tus pensamientos porque se convierten en palabras. Vigila tus palabras porque se convierten en actos. Vigila tus actos porque se convierten en hábitos. Vigila tus hábitos porque se convierten en carácter. Vigila tu carácter, porque se convierte en tu destino". Las prácticas que he mencionado, en diferente medida, constituyen un acercamiento a este objetivo, objetivo no sólo legítimo, sino, como ha señalado el Dalai Lama, el más importante y universal para los humanos. Desgraciadamente, no hay recetas para ser feliz, y aunque las hubiera, no las seguiríamos: encontrar lo que es mejor para uno es una tarea individual, yo diría que la tarea de toda una vida, y aquí viene a cuento recordar al humanista Carl Rogers y su acertado texto sobre "El proceso de convertirse en persona". También es importante recordar la filosofia oriental y zen que enseñan que no hay que pretender ser feliz; por tanto, no tengan empeño en ser felices; simplemente, permítanselo. Recuerden, para terminar, los muchos datos que señalan que las mejores circunstancias no aseguran los mejores momentos, mientras que, a veces, en circunstancias difíciles las personas se han sentido muy completas, han crecido y han cambiado, a veces de forma permanente y definitiva, para mejor. Los medios de comunicación nos recuerdan diariamente a esas personas que, como la azafata canaria superviviente del accidente reciente de Barajas, o las víctimas de agresiones gravísimas que han estado a punto de morir 
(véase el testimonio impactante de una mujer sudafricana en El País del pasado 24 de agosto), nos sonríen sin asomo de trauma o rencor, o más aún, el mensaje conmovedor- como el de La última conferencia, de Randy Paush, www.randypaush.com- de quienes se despiden de la vida alertándonos de que no perdamos tiempo en desviarnos de lo verdaderamente importante.

\section{REFERENCIAS}

Avia, M.D. (2006). La psicología positiva y la moda de la "soft psychology". Clínica y Salud, 17, 239-244

Avia, M.D.\& Vázquez, C (1997). Optimismo inteligente. Madrid, Alianza Editorial

Bryant, F. B. (2007). The process of savoring. A new model of positive experience. $\mathrm{NJ}$, Erlbaum.

Crosby, J.O.(Ed, 1992): Francisco de Quevedo. Poesía varia. Madrid, Cátedra

Dalai Lama y H. C. Cutler; (1999). El arte de la felicidad. Barcelona, Random House-Mondadori.

Deci, E. L. \& Ryan, R. M (2000). The "What" and "why" of goal pursuits: human needs and the self-determination of behavior. Psychological Inquiry, 11, 227-268

Diener, E. \& Oishi, S. (2005). The nonobvious social psychology of happiness. Psychological Inquiry, 16, 162-167

Fava, G., Rafanelli, C. Cazzaro, M., Conti, S,\& Grandi, S. (1998). Well-being therapy: a novel psychotherapeutic approach for residual symptoms of affective disorders. Psychological Medicine, $28,475-480$

Fava, G. Ruini, C, Rafanelli, C, Finos, L., Salmaso, L., Mangelli, L. \& Siragatti, S. (2005). Well-being therapy of generalized anxiety disorder. Psychotherapy and Psychosomatics, 74, 26-30.

Fordyce, M (1983). A program to increase happiness: Further studies. Journal of Counselling Psychology, 30, 483-498

Freedberg, D. \& Gallese, V (2007). Motion, emotion and empathy in esthetic experience. ScienceDirect, 11, 197-203

Frijda, N (1996). Las leyes de la emoción. Traducción de M. D. Avia y V. Sánchez de Zavala (orig.1988) En M. D. Avia y M. L. Sánchez 
Bernardos (eds): Personalidad: aspectos cognitivos y sociales. Madrid, Pirámide

Gillham, J.E., Reivich, K.J., Jaycox, L.H., \& Seligman, M.P. (1995).

Prevention of depressive symptoms in school children: two-year follow-up. Psychological Science, 6, 343-351

Kachorek, L.V., Exline, J.L., Campbell, W.K., Baumeister, R. F., Joiner, T.E.\& Krueger, J. I. (2004): Humility and modesty. En C. Peterson, y M.P. Seligman, (2004). Character strengths and virtues. Oxford University Press- APA University Press., pp. 461-476

Kanfer, F. H. \& Schefft, B.K. (1988).Guiding the process of therapeutic change. Champaign, III, Research Press.

Lazarus, R. (2003). Does the positive psychology movement have legs? Psychological Inquiry, 14, 93-109

Leary, M.R. Hancock (2007), Tate, E.B., Adams, C.E, Batts, A.A \& Hancock, J (en prensa) Self-compassion and reactions to unpleasant self-relevant events: the implications of treating ourselves kindly. Journal of Personality and Social Psychology. 5, 887-904.

Lutz, A., Brefczynnski-Lewis, J., Johnstone, T., \& Davidson, R. J (2008). Regulation of the neural circuitry of emotion by compassion meditation: effects of meditative expertise., PlusOne, 3, 1-9 Lyubomirski, S., Sheldon, K.M., \& Schkade, D. (2005). Pursuing happiness: the architecture of sustainable change. Review of General Psychology, 55, 95-107

Martínez-Martí, M. L, Avia, M. D. \& Hernández Lloreda, M.J (2007). Effects of a counting blessings intervention on subjective wellbeing: is really gratitude the main mediator? Artículo presentado para publicación.

Neff, K. D. (2003). Self-compassion as an alternative conceptualization of a healthy attitude towards oneself. Self and Identity, 2, $85,-102$

Neff, K.D., Kirkpatrick, K. \& Rude, S.S. (2007) Self-compassion and adaptive psychological functioning. Journal of Research in Personality, 41, 139-154

Neff, K.D., Rude, S.S. \& Kirkpatrick, K. (2007) An examination of selfcompassion in relation to positive psychological functioning and personality traits. Journal of Research in Personality, 908-916 
Peterson. C. (2006). A premier in positive psychology. NY, Oxford University Press

Peterson, C. y Seligman, M.P. (2004). Character strengths and virtues. Oxford University Press- APA University Press.

Prieto-Ursúa, M (2006). Psicología positiva: una moda polémica. Clínica y Salud, 17, 319-338

Rogers, C (1971). El proceso de convertirse en persona. Buenos Aires, Paidos.

Ryff, C.D. y Singer, B.H. (1996). Psychological well-being: measuring and implications for psychotherapy research. Psychotherapy and Psychosomatics, 65, 14-23

Seligman, M.P.(2004) La auténtica felicidad. Madrid, Javier Vergara, 2003

Seligman, M.P., Steen, T.S., Park, N. y Peterson, C. (2005). Positive psychology progress: empirical validation of interventions. American Psychologist, 60, 410- 421.

Shapiro, S.C., Astin, J.A., Bishop, S.R. y Cordova, M. (2005) Mindfulness-based stress reduction for health care professionals: results of a randomized trial. International Journal of Stress Management, 12, 164-176

Shelp, E.E (1984) Courage: a neglected virtue in the patient-physician relationship. Social Science and Medicine, 18, 351-360.

Steiner, G (2007). Diez (posibles) razones para la tristeza del pensamiento. Madrid, Siruela

Taylor, S. E. (1989). Positive illusions. NY, Basic Books.

Taylor, S.E.\& Brown, J.D. (1988). Illusion and well-being; a social psychological perspective on mental health. Psychological Bulletin, 103, 193-210

Vázquez, C., Hervás, G.,\& Ho, S. M.Y. (2006). Intervenciones clínicas basadas en la psicología positiva; Fundamentos y aplicaciones. Psicología conductual, 14, 401-432

Worthington, E. L. Sandage, S.J, y Berry, J.W (2000). Group interventions to promote forgiveness: what researchers and clinicians ought to know. En M.E. McCullough., K.I. Pargament \& C. Thoresen (Eds): Forgiveness: Theory, research and practice. NY, Guilford Press, pp. 228-251 